\title{
Digital Journalism and Risk Communication Practice for Public Health Humanitarian Emergencies Response in Africa
}

\author{
Ernest Tambo ${ }^{1,2 *}$, Adama Kazienga ${ }^{1}$ and Marcel Fogang ${ }^{1}$
}

${ }^{1}$ Africa Intelligence and Surveillance, Communication and Response (Africa DISCoR) Foundation, Yaoundé, Republic of Cameroon

${ }^{2}$ Higher Institute of Health Sciences, Université des Montagnes, Bangangté, Cameroon

\begin{abstract}
Contemporary West Africa Ebola virus disease outbreak (2013-2016), conflict and insurgency related insecurity and health inequity in Democratic Republic of Congo, Somalia and South Sudan, Libya and Nigeria are major source of public health emergencies and disasters humanitarian crises. Little is documented o the effectiveness of social media and digital journalism opportunities and challenges in early threat detection and emergency rapid response in Africa. This paper examines the value of social media and digital journalism risk communication transformation and resiliency strategies in public health emergencies crises reduction and preventive countermeasures amongst vulnerable communities in Africa. The internet penetration ranged in the selected African countries from $4 \%$ in Niger to $86 \%$ in Kenya whereas in the selected developed countries, it was from $84 \%$ to $98 \%$. Sustained impact on the quality of health information for populations in low resource settings in needed in reducing the level of the hazard and exposure extend related public health emergencies and humanitarian crises threats, vulnerabilities and consequences assessment towards share existing local/regional capacities, timely, reliable and useful information communication in pre, during and post events. Authors emphasize that strengthening interdisciplinary social media and digital journalism collaboration and partnership effectiveness, capacity building and training for health professionals and institutions support mechanism to coordinate risk communication preparedness and planning strategies underscore the risk of highly pathogenic diseases and others public health emergencies in developing countries including Africa. Updating and strengthening effective and sustainable digital journalism and mass media strategies implementation in minimizing public and global health emergencies, risk prevention and preparedness management capacity development is needed to enhance against backslashes and challenges. The value of interdisciplinary social media and digital journalism platforms and collaborative research can lead to more reliable, trustful and effective public information, in reducing emerging human-animal-environment interface and cyber-attacks threats.
\end{abstract}

Keywords: Digital journalism; Social media; Resiliency humanitarian crisis; Emergency; Risk communication; Mobile health; Practice; Africa

\section{Introduction}

The changing pattern of infectious diseases outbreaks, droughts, floods and related public health and socio-economic impact underscore the urgent need for robust and effective leadership commitment and investment. Diseases and/or infections that are naturally "transmissible from vertebrate animals to man" are classified as a zoonosis [1]. According to recent definition by the World Health Organization (WHO), any disease or infection that is naturally transmissible from vertebrate animals to humans co-evolutionary struggle and vice versa is classified as a zoonotic [2]. Africa is still responsible for $24 \%$ of the global health burden of zoonotic diseases epidemics including bacteria (salmonellosis, plague, anthrax, and leptospirosis), parasites (taeniasis, hydatidosis, and toxoplasmosis), viruses (rabies, Japanese encephalitis, avian influenza, Nipah, severe acute respiratory syndrome (SARS), avian influenza), and unconventional agents (bovine spongiform encephalopathy). For example, the outbreak of Ebola in 2014-2016, which killed over 11,000 deaths in most affected West Africa countries (Guinea, Sierra Leone, Liberia) as a reminder of the continent's unending susceptibility to epidemics [1,2]. The estrangement or lack of trust and confidence has been widely traced to weak health systems and chronic shortage in resources, prevailing or suspicion and reticence on emerging pandemics and existing outbreaks still ravaging different vulnerable communities and populations, despite the deployment of multiple advocacy tactics.

Advancements in digital media and communications technology have generated considerable optimism on the role of social media in achieving developmental and public health outcomes globally. The unprecedented availability of digital devices and platforms has also prompted different development institutions to design and implement a range of social media interventions for social and behavior change in facilitating effective preventive social media and digital journalism risk communication [3,4]. Communication is central to public health delivery, and advances in digital media and communication technology hold significant prospects for addressing major public health and development issues confronting the continent [3]. Risk communication is as an interactive exchange of information and opinion amongst individuals, groups and institutions, with the goal of assessing, minimizing and regulating health risks. In essence, it is the sharing of information with the public or institutions about the probability and consequences of harmful events and therefore enables the public to respond to the crisis and reduces the possibility of misinformation. Effective risk communication involves trust between the organization and people communicating the risk and the audience receiving information to further define risk communication as an interactive process that exchanges information and opinion amongst

${ }^{*}$ Corresponding author: Ernest Tambo, Department Biochemistry and Pharmaceutical Sciences, Higher Institute of Health Sciences, Université des Montagnes, Bangangté, Cameroon, Tel: (+237)2430025141; E-mail: tambo0711@gmail.com

Received April 25, 2018; Accepted August 09, 2018; Published August 16, 2018

Citation: Tambo E, Kazienga A, Fogang M (2018) Digital Journalism and Risk Communication Practice for Public Health Humanitarian Emergencies Response in Africa. J Mass Communicat Journalism 8: 383. doi: 10.4172/2165-7912.1000383

Copyright: $\odot 2018$ Tambo E, et al. This is an open-access article distributed under the terms of the Creative Commons Attribution License, which permits unrestricted use, distribution, and reproduction in any medium, provided the original author and source are credited. 
individuals, groups and institutions [4]. It usually involves multiple messages regarding the nature of the risk and expresses concerns, opinions and reactions to risk messages, or to legal and institutional arrangements for risk management. Risk communication differs from other communication as it is a political process that can present ethical problems. Moreover, risk communication differs from public awareness, as it not only aims to educate the public on risks but is also a reciprocal process, meaning that different stakeholders listen to each other and forms a common understanding about risks, their acceptability and actions to reduce those risks [5]. Also, the aim of risk communication is to ensure agreement between stakeholders on different risk management measures and to improve transparency of decisions and increase the potential acceptance of the outcome. Such optimism is grounded in the increasing levels of internet penetration, health information, facilitate interactivity, and promote confidentiality of use. Such transformative effect of mobile technology as well as intrinsic characteristics of social media which include interactivity, genuine dialogue, speed, multimodality, user-generated content, mass customization, horizontal communication, and multi-directionality of information [6,7]. Other studies have also underscored the significance of information and communications technologies in transforming health communication practices.

However, digital journalists are not necessarily trained to provide adequate information about outbreaks. Operational studies on funding and humanitarian assistance interventions evaluation with the potential to provide addition texture between country strategies and outcomes is crucial in understanding of socio-cultural factors in the uptake of health information [3]. Almost none of the articles identifying opposing situations mentioned clear, comprehensive, accessible, and constructive public health messages value on social media journalism and effective risk communication in public health emergencies and humanitarian crises in strengthening national risk communications strategies that incorporate needs [2-4]. Verifying and validating whether a special social medial risk communication plan in place can assist and support vulnerable people in remote rural areas with limited digital coverage access. Monitoring and evaluations of social journalism in effective epidemic humanitarian needs, genderbased violence and conflicts resolutions preventive countermeasures must also analyze in the socio-cultural, political and or geographic context and root-causes that could affect mitigating and handling future pandemics threats effectively[2,5].

The use of electronic communication for public health emergencies and humanitarian assistance purposes predates current advances in digital media. Advancing digital information technology including social media journalism opportunities and benefits for healthcare delivery, public health emergencies and humanitarian assistance, response logistics and supply chain management involved didactic patient or vulnerable population risk communication through eventcentered approaches and telemedicine, websites, emails and podcasts such as blogs, wikies and mobile smart phones[2,6,7]. Technologicallyenabled reliable and efficient journalism solutions were also intended to provide alternative sources of information in the health sector, including data sharing platforms and creating interaction source opportunities among media personnel, frontline or community health professionals and affected populations [3-5]. Nevertheless, developments in internet technology and an unprecedented growth in mobile infrastructure have expanded the deployment of social media devices for health communication and education [6,7]. Social media can both help facilitate information sharing and be problematic in spreading rumors during normal (or seasonally expected) health events and health crises $[2,8]$. Public health agencies and other organizations can use social media to disseminate time-sensitive health information, promote information sharing to encourage behavioral changes (including corrective changes during potential health crises). This can be a platform for conversation between agencies and constituents (rather than just as an information provider) and allow the public to provide useful information and feedback. Managing misinformation during health crises is an important role that health agencies and other organizations have been forced to take on during events such as the 2014 Ebola crisis $[8,9]$. Thus, it is crucial that public health agencies and organizations are equipped before a crisis with strategies, educational material, messages and an appropriate staff or volunteer social media and digital journalism management plan to counter misinformation. Acceleration of available "mobile health (mHealth)" devices such as wearable biosensors applications and social media platforms for tracking both personal health and allowing healthcare practitioners to track patients remotely from routine and emergency personal and communities primary healthcare data sharing and communication, is essential in predictive and preventative monitoring public health emergencies and disaster crises programs [10-12].

In contrast, sharing social media and internet-based emergency health data has prompted industry-wide questions about privacy, culture and deeper rights-based actions how both sensitive personal health information and patient information can be protected if a platform is hacked or a wearable device is lost $[1,2,12]$. While social media has manifold applications in public health, it has also been used by physicians and other health professionals to achieve important public health emergencies, care delivery and clinical practice, education and research beneficial applications. Those allow for better risk prioritization and planning of public health preparedness, transparency in the context of risk communications is invaluable if emergency/response managers seek to gain and/or maintain public trust and participative resiliency [13]

This paper examines the value of social media and digital journalism risk communication transformation and resiliency strategies in public health emergencies and disaster crises reduction and preventive countermeasures amongst vulnerable populations and communities in Africa.

\section{Results and Discussions}

\section{Community perceptions of social media and communication change and evolving health issues}

The socio-demographic indicators as the multidimensional poverty index (MPI) and the literacy rate were used coupled with the internet penetration and the active using of the social media of selected African and developed countries. The MPI has been evaluated using three main dimensions which are education, health and standard of living. The parameter taking in account in the education were the year of schooling, the school attendance while it were child mortality, nutrition for the health dimension and electricity, sanitation, water, floor, cooking fuel and assets for the standard of living dimension. It can be seen from Table 1 that there was association between the MPI and the literacy rate as well as the internet penetration and social media use. Thus, the countries with lowest poverty index had high literacy rate and also high internet penetration. The internet penetration ranged in the selected African countries from $4 \%$ in Niger to $86 \%$ in Kenya whereas in the selected developed countries, it was from $84 \%$ to $98 \%$. Although, the active users of social media users in the selected developed countries compared to the internet penetration remained 


\begin{tabular}{|c|c|c|c|c|c|c|c|c|c|}
\hline Country & Population & \begin{tabular}{|} 
Multi-dimensional \\
Poverty Index \\
(MPI)
\end{tabular} & $\begin{array}{l}\text { Literacy } \\
\text { rate } \\
(\%)\end{array}$ & \begin{tabular}{|c|} 
ICT \\
$\begin{array}{c}\text { Development } \\
\text { rank }\end{array}$
\end{tabular} & $\begin{array}{c}\text { Internet } \\
\text { Penetration (\% } \\
\text { Population) }\end{array}$ & $\begin{array}{c}\text { Active social } \\
\text { media user ( } \% \\
\text { Population) }\end{array}$ & $\begin{array}{l}\text { Facebook } \\
\text { users (\%) }\end{array}$ & $\begin{array}{l}\text { Twitter users } \\
\text { (\% population) }\end{array}$ & $\begin{array}{l}\text { Youtube users } \\
\text { (\% population) }\end{array}$ \\
\hline Kenya & 48466928 & 0.187 & 78 & 138 & 86 & 15 & 12,79 & 8.08 & 3.18 \\
\hline South Africa & 55436360 & 0.036 & 94.3 & 92 & 54 & 32 & 28,86 & 6.76 & 2.42 \\
\hline Morocco & 35241418 & 0.067 & 72.4 & 100 & 63 & 44 & 34,05 & 2.22 & 37.2 \\
\hline Cabo verde & 533468 & - & 87.6 & - & 48 & 45 & 39,37 & 1.46 & 5.58 \\
\hline Algeria & 41063753 & 0.006 & 80.2 & 102 & 50 & 50 & 43,83 & 3.26 & 42.31 \\
\hline Ghana & 28656723 & 0.156 & 76.6 & 116 & 35 & 19 & 13,96 & 5.82 & 3.82 \\
\hline Namibia & 2568569 & 0.193 & 81.9 & 118 & 31 & 24 & 20,24 & 3.61 & 6.89 \\
\hline Rwanda & 12159586 & 0.259 & 70.5 & 153 & 30 & 4 & 4,03 & 2.02 & 0.93 \\
\hline Swaziland & 1320356 & 0.066 & 87.5 & - & 32 & 14 & 12,12 & 3.9 & 3.25 \\
\hline Lesotho & 2185159 & 0.140 & 79.4 & & 27 & 15 & 13,27 & 3.51 & 1.87 \\
\hline Burkina Faso & 19173322 & 0.535 & 36 & 133 & 19 & 5 & 3,13 & 1.01 & 0.72 \\
\hline Benin & 11458611 & 0.307 & 38.4 & 161 & 33 & 10 & 6,98 & 2.79 & 1.83 \\
\hline Guinea & 13290659 & 0.459 & 30.4 & 166 & 12 & 12 & 7,15 & 2.49 & 0.57 \\
\hline Niger & 21563607 & 0.605 & 19.1 & - & 4 & 2 & 1,30 & 1.9 & 0.79 \\
\hline Mali & 18689966 & 0.457 & 38.7 & 155 & 66 & 9 & 5,35 & 2.36 & 0.75 \\
\hline Norway & 5330800 & NA & 100 & 8 & 98 & 69 & 63.8 & 6.17 & 3.5 \\
\hline United Kingdom & 65511098 & NA & 99 & 5 & 95 & 66 & 59.5 & 11.3 & 2.46 \\
\hline USA & 363224000 & NA & 86 & 16 & 88 & 71 & 72.42 & 4.04 & 0.99 \\
\hline Singapore & 5791901 & NA & 96.8 & 18 & 84 & 83 & 81.5 & 2.17 & 8.19 \\
\hline
\end{tabular}

Table 1: Social media and Internet-based communication and penetration in some selected countries in Africa in 2017

higher, it was very low in the selected African countries. The Facebook platform was the most predominant social media used and followed respectively by Twitter and YouTube.

Furthermore, effectiveness of community social media communication networking and radio and mobile strategies requires effective and dignified public awareness and public education and adaptation good practice. Ensuring leadership policy and engagement is needed in harnessing social journalism awareness, perceived risk communication and confidence, risk information source and measures, and social norms and pressures cost of behavior change strategies. This is crucial when developing messages, communication experts also need to understand the comprehension and literacy level in public health emergencies and disaster humanitarian crises. It also requires leveraging on lessons learnt, experiences and action learned in delivering and supporting health communication in response to underscores the need for the global community to plan and invest in support preparedness planning and communication long before any crises take hold. In addition, this leads to ensure that effective media and communication plays a central role in reducing the impact of future crisis events and recommendations to ensure that media and communication are used to their full potential during other disease outbreaks or humanitarian crises $[14,15]$.

Ever-increasing use of social media tools, and that abdicating their leadership role on the issues raised by these tools would have in improving social medial informed consent process and evidencebased engagement and enhancing information access and uptake in understanding the value of risk communication in humanitarian emergencies. Fostering humanitarian risk or threats forecasting and modeling to frontline decision making strategies and humanitarian resource allocation and logistics management by engaging multisectorial stakeholders around a risk assessment developed for risks affecting public health emergencies response. Furthermore, provide a systematic, transparent and evidence-based approach to identify and classify priority hazards by level of risk, availability of safe shelter and care service delivery, and hygiene conditions before, during and after a disaster can greatly determine the impact on a community's health and well-being. Robust interdisciplinary social journalism framework and target outcomes in designing and implementing social media programs for public health services delivery and livelihoods is necessary $[3,16]$. Health promotion has always required insights from different intellectual domains, but in the digital age, heightened public and various professionals engagement is more crucial for effective delivery of social media interventions. A wider social media journalism space for precarious and vulnerable users of social media needs to be created for effective design and execution of such programs and eventually can influence the current development discourse and public event-based emergency response[7,17].

Health practitioners, researchers and agencies should also consider the potential benefits of using social media for obtaining rapid and timely data about trends and patterns in health and some harmful effects. For example, health professionals and agencies now face is the ability to respond publicly and in a timely manner to the spread of misinformation and health-related rumors during public health events, as the 2014 Ebola crisis illustrated $[2,9,10]$. Social media "storms" are able to cause and create shared public responses that may or may not be appropriate for the health event. Strengthening local and global health agencies needs and priorities with concerted actions plans in place ahead of time to be able to respond to and counter misinformation or support accurate information shared via social media and social journalism communication in social mobilization, health education and livelihood outreach $[9,11]$. Ensuring compliance with standards of online professionalism and patient privacy protection to patients, medical professionals in online discussions is crucial intackling current public health emergencies challenges and emerging pandemics threats concerns relating to social media in healthcare. As well as proliferation of physician and hospital rating and review sites, which often lack sufficient patient participation to provide an accurate reflection of satisfaction with services? Hospital and physician participation in social media platforms helps them to manage their reputation by elevating their own content in search results, while also reducing the influence 
of misinformation, or information sharing of public health concerns, to ensure that strategies to address misinformation are stronger than ever [18].

\section{Strengthening public health emergencies surveillance and healthcare service delivery equity through social and mass media reengineering}

Our finding showed that risk communication and digital journalism timeliness and transparency determined when and how much emergency response and resiliency were needed to avert and contain any emergency threats and impact. Also, coherent awareness and social mobilization through radio, digital journalism was capital coupled with lessons learnt and experiences those were significant transformation and behavioral changes to survival resiliency in recovery and rebuilding processes. Thus, digital technology systems and internet penetration has been described as 'phenomenal' and the emergence of mobile technology is generally perceived as the 'second communications revolution on the frequency and magnitude of public health emergencies. Local and global digital journalism systemic policy and programs implementation is needed for effective social media social mobilization, community awareness and power for wider development outcomes. Although many African countries have put in place laws and regulations to harness ICT, local radio and television channels and directly phoning for the continent, they need to respond to the public health and socio-behavioral dimensions in the context epidemics crises and humanitarian emergency needs [19].

More investment and effectiveness of early warning information metrics is needed in social medial and internet/e-health communication policy and daily risk communication strategies practice implementation. Appropriate levels of social journalism preparedness and response capacity development can be used in effective risk communication, awareness campaigns to rapid containment and recovery. While it is not possible to use social journalisms prevent these health emergencies, their adverse impact can be mitigated through effective risk communications have the potential for major economic losses. Hazards preparedness and response, risk management transparency and accountability to inform, connect and empower people are crucial in all types of hazards local and global mitigation and advocacy priority. This is needed in understanding the attributed risk factors such as late hazard detection and risk communication, unpreparedness and late response to increased human migration and animals' movements or transhumance, expansion of international travel and trade, social and climate changes and community resistance in Africa. Social media and digital solutions have been deployed for different sectors of society, including health education and communication. A host of countryspecific and multi-country social media initiatives have been designed for addressing the multifaceted public health dilemmas confronting the continent [20].

Risk communication can be used as an effective tool to promote mitigation and preparedness for infectious disease epidemics and humanitarian disasters crises. But also, in delivering a short script explaining the nature and effects of an influenza pandemic and Ebola to Cholera and Polio epidemics and immunizations coverage significant improvements in knowledge and outcomes measures $[2,8]$. Likewise, to improve understanding of viruses to facilitate response to risk communication about pandemic and epidemic threats through social media and internet platforms. Educational videos could be used and coupled with community-based preparedness discussions on community health promotion and risk communication preparedness program from preparedness meeting. In addition, having a risk mapping, an emergency supplies, a plan for vulnerable people and having an evacuation drill to tackle factors relating to personal circumstances, beliefs and attitudes cultural and societal response.

Integrating risk reduction methodologies into developmental initiatives to build resilience in households and communities those affected and involved is a crucial capacity to ensuring communication efforts are effective and support sound emergency management decision-making. Understanding community perceptions of risk and adapting communication messages, materials and strategies require meaningful engagement with those affected and involved [6,21]. Health systems is increasingly turning to social media to support, promote and increase the spread of information and data, clinical healthcare to public health campaigns in order to improve both personal and community health practices. Therefore, there is an increased attention in the media and outside the immediate community and country syndromic surveillance, which relies on watching data streams ranging from patient intake to over-the-counter medication purchases. This leads to determine and predict health trends, can potentially employ this information shared via social media channels to inform the implementation of recovery, reconstruction, rehabilitation and restoration of services and other health related activities [12,16,17]. There will continue to be advancements in mobile health (mHealth) that will unveil new questions about data sharing and privacy, and while encouraging the use of social media. Social media has provided a space to share preventative information and enabled the creation of support structures to track personal health and build patient-to-patient support networks post-diagnosis to dispute rumors and misinformation countermeasures to raise awareness within their communities.

It is both responding to the needs of the health industry and creating numerous challenges that health professionals are required to keep up with ranging from privacy issues related to social media sharing practices by communicating more rapidly, access supplemental research data, and arm themselves with pertinent health information. There is a need to manage their own health and those of others has been propelled by access to information via social media, coupled with the ubiquity of cellular devices in social and digital technology has great potential for transforming health education and communication globally[3,7].

Social journalism and social media have been responsible for relevant behavioural and socio-economic changes in both personal and community health, especially by making it easier for large numbers of people to rapidly share information [3,5,7]. This has brought with it both strengths, such as the ability to have preventative and diagnostic/reactive information widely available, and challenges, such as the potential for misinformation to rapidly circulate without the involvement of health practitioners, institutions and organizations. However, significant caution is necessary on its perceived impact within the pathway of social and behavior change. Thus, continuous integration of digital journalism and social media platforms (Android Apps, Facebook, Twitter and Google Trends) lessons learnt and technical assistance improvements is necessary on how to maximize its value and power for public health goods and benefits. This leads to identify topics of interest on the issue and communicate such to the public health emergencies, providing the public with the much-needed information on screening, diagnosis and treatment $[4,7,9,12]$.

Enabling social networking platforms capacity building for community-patient-provider benefits 
Our results reported that increasing levels of digital journalism such as social media and internet penetration cost-effective access and uptake can promote information use and practice to pervasiveness of mobile devices and social networking services. It has potential and impact in public health emergencies and humanitarian crises communication has led to the burgeoning of E-Health communication, multifaceted: addressing the information gap on specific issues, changing social norms and promoting a positive attitude among the target audience. However, the use of social media seems to be more for 'information blast', 'message storm' or 'buzz creation' or 'noise' around specific health issues and at-risk to adopt protective behaviors in an emergency in Africa.

Well-planned series of actions, combining different methods, techniques and tools to achieve an intended change or objective utilizing the available resources within a specific timeframe communication strategy is a well-organized sequence of actions to achieve specific objectives through the implementation of a mix of communication methods, techniques and approaches $[3,5,9,18,20]$. These include a wide range of platforms, comprising (i) networking sites such as Facebook, YouTube and LinkedIn, etc.; (ii) micro blogging platforms such as Twitter, Wikkis, and (iii) mobile messaging services such Instant Messaging, SMS/MMS. Some of the interventions utilize single media platforms such as Twitter or Facebook, while others adopt multi-media platforms. However, it is argued that integration of social media into existing traditional multi-media communication initiatives. Digital solutions have been deployed for different sectors of society, including health education and communication. Social media platforms have now become indispensable for health literacy and an overall improvement of health outcomes $[7,9,21,22]$.

Furthermore, some forms of social medial and internet communication interventions in revamping persisting fear, mistrust, and opposition and inequities due to lack of information and/or information overload amongst vulnerable. This can help to support efficient and viable real-time data collection and disease surveillance, health information management and point of care, treatment compliance and emergency response. Other areas of application include health information dissemination, health care monitoring, training of health care workers, tracking of disease outbreak and diagnostic support through tailored education, information dissemination and community-based awareness programs [13]. These are required in effective and comprehensive capacity building and training in digital journalism and professionalism. This is a prime candidate for delivery via online social collaboration platforms and cultural aspects of value of risk information and communication that would be impractical without that overcome risk communication barriers of time and space opportunities for beneficial applications. It also provides the best ways to mitigate concerns that continue to develop applications for sharing personal health information and ask people to share health data about themselves, keeping up with the requirements of personal and patient privacy will be vital in order to protect social media users $[13,19,23]$. Moreover, being able to share information about health both our own and that of others via social media more rapidly than ever before. The verification of this shared health information, especially as it relates to fast-moving epidemics or heightened seasonal health concerns is crucial to keeping the public accurately informed on potential use of social media and communication context.

Besides, operational research is necessary to generate evidence for effective programming; more cutting-edge perspectives and evidence to advance current thinking have become increasing fundamental risk community and resiliency tactics research translation should include impact and outcomes of interventions and greater [17,24]. More amenable and accessible monitoring and evaluation platforms and empowerment skills and insights required for effective social media and digital communication programming low-cost ways to impact organizational transparency and practice of communication in emergency response. This is a need for better health and science reporting, governmental agencies and foundations have developed programs for journalists that seek to provide them with experiences that will deepen their subject matter knowledge and strengthen their reporting[24,25].

\section{Improving digital journalism practice in communication safety, care delivery and rapid response effectiveness}

Increasingly local and internal journalists' scientific knowledge based on social media and internet communication network and partnership cooperation has shown to enhance discriminate between social networking (e.g., Facebook), social bookmarking (e.g., Digg), video-sharing (e.g., YouTube), picture-sharing (e.g., Flickr), professional networking (e.g., LinkedIn), user forums, blogs and microblogging (e.g., Twitter). This could help them to broadcast the correct information about an associated risk of infection with potential epidemics and also could ease implementation of efficient public health measures. Digital journalists from high-income countries could share their knowledge and experience with their African counterparts during public health crises. This leads to help raise a community's awareness including social networks, microblogs, mobile text messages, and Rich Site Summary (RSS) feeds have emerged from a novelty a few years ago to an important and sophisticated set of contemporary communication tools during Ebola and Zika virus outbreaks. In addition, HCWs needed to develop an effective communication campaign that involved dialogue with those affected, including frontline HCWs to understand their perception about the trial. In case of a positive perception of the vaccine trial, this may as well mean that everyone would want to be vaccinated $[2,5,9,18,26]$.

Our findings indicate the active social media users in the selected countries in 2018 (percentage of population). It can be seen from the graph that there was three main levels as high, moderate and low (Figure 1). The majority of the developed countries population used actively the social media with at least $66 \%$ of the total population while it ranged from $2 \%$ to $32 \%$ in the selected African countries. The highest level of active social media users was documented in Algeria with 50\% while the lowest was reported in Niger with only $2 \%$ of the total population use actively the social media. We documented that visual content easily distill complex information and help quick response actions, and emotional or compassionately deeper engagement and participation in emergencies response and recovery support or participation to affected people or communities.

Effectively communicating in mass drug administration and mass vaccination campaign impact of media development, defined to include not only the professional capacity of journalists to report on science and health. But also the enabling environment for an independent and pluralistic media sector, on the delivery of public health information that posed a real challenge as to how to make the public understand that only members of the community who fit the trial criteria would be vaccinated $[12,16]$. Some humanitarian originations, institutions and non-governmental organizations are accustomed to participating in such capacity-building programs and principle to ensure that future risks of emergencies and disasters reductions. Mobile health is often 


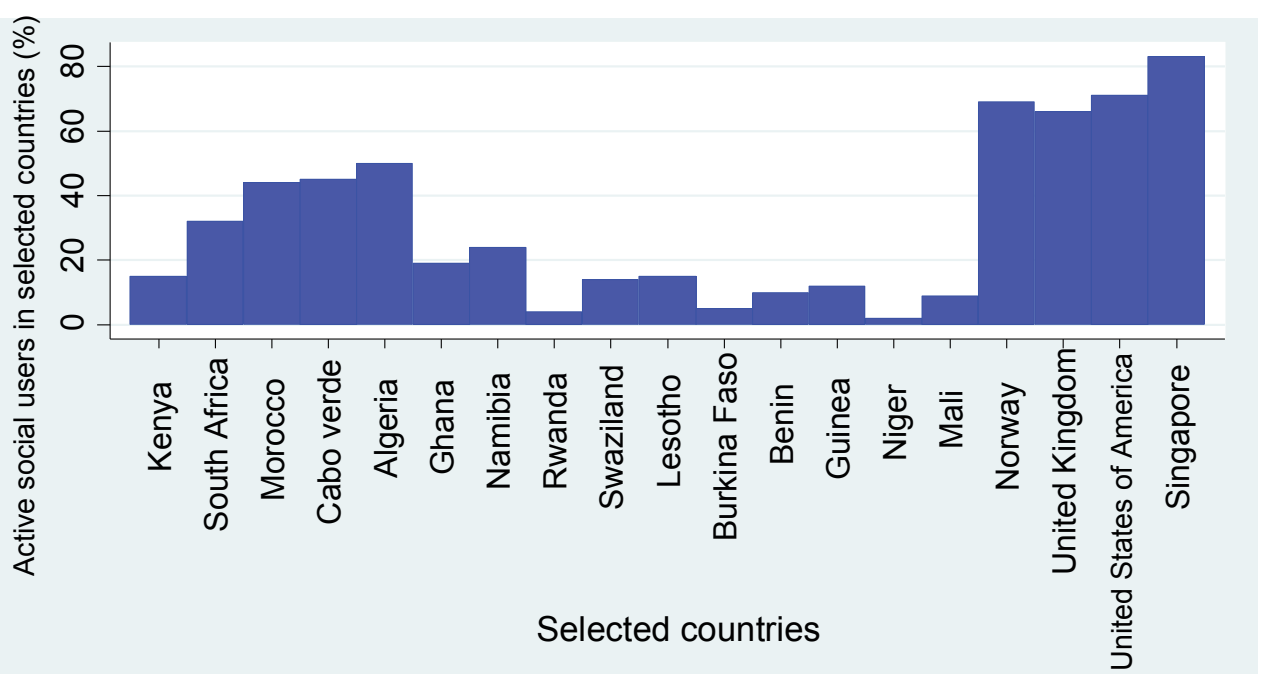

Figure 1: Distribution of active social media users in risk communication strategy in selected countries.

described as a 'game-changing' technological platform. Unlike other mass communication platforms such as television and radio, mobiles cannot only be used to provide information and enable people to interact with that information. Furthermore, it aimed at delivering services and strengthens health systems, identification and mapping of hazardous areas inform the decisions for building critical infrastructure such as water, sanitation and health systems and services to manage the risks of biological hazards as well as other types of emergencies. In other words, "mobile telephony can unite both the educational and clinical functions of mHealth in one device" in defining impact of computer and internet technologies innovation in preparedness with the development of preparedness apps, which are unique in being able to add content in direct response to users' needs $[6,12,22]$ affirms that using social media for health communication will eliminate some of the inherent limitations of traditional health communication through improved, contextual, interactivity and mixed media utilization. One could also argue that digitally enabled social media interventions such as mobile phones, instant messaging, chat room forums and social networking sites are also particularly relevant for communication of sexual and reproductive health issue, no shortage of analysis on the operational issues and systemic flaws that shaped both the epidemic and the response and building relationships through open dialogue internally and externally, providing both opportunities and challenges (Figure 1).

The role of social journalism and digital social advertising or marketing suggests that advances in digital information technology platform, inter-operability and data sharing offers immense opportunities for health awareness and promotion. This is also important in engaging health professionals and care-providers with their patients or affected or most vulnerable groups through personalized care and consultation, motivational advice, aspirations and social mobilization in transformative behavioural changes, participative learning and empowerment in tackling emergencies events, disaster issues and challenges[12,15,19]. Hence, the new digital/ social media journalism paradigm shift thinking and practice offer a new benefits compared to traditional radio and TV methods of social marketing and communication for development. This assertion is consistent with who contend that more than any other time in history, social media offers timely and credible health information, critical for improving public health outcomes quickly and directly, learning learn about how local media performance and effectiveness [12,20]. Digital journalism and social media risk communications should aim at providing accurate, timely information to the public, to health care workers, and to those setting policy at the local and national level and platforms to disseminate these messages rather than as professionals tasked with shaping vital lifesaving information that were broadcast across FM networks and on the few local television station by providing educational videos on general topics $[1,3,10,12,22]$. Also, it enables deeper and more meaningful online video/sms face-to-face discussions to address particular patient issues or risk, participation and active dissemination of medical or disaster threat myths and misinformation by self-interested propagandist and recruiting subjects for clinical trials or immunization resistance to access and uptake to life saving information during humanitarian crises or emergency events. Independent journalists provide accountability and risk communication transparency can also assist to signaling gaps in service delivery by investigating and reporting on abuses of trust [12,14]. Public emergencies and humanitarian organizations or NGOs recovery and rebuilding programs for survivors grapple with stigma and families and communities losses consequences and other vulnerable populations can help by enabling success stories to be told and shared lessons learnt and best practices during West Africa Ebola outbreaks, humanitarian assistance in refugees camps and displaced populations interventions impact became increasingly evident that public resistance reduction and ablation can be achieved. Consistent and simple, effective and dignified communication and educational messaging programs were a significant barrier to the adoption of health seeking behaviors in communities at risk or fed both fear driven responses and the stigmatization of affected individuals and communities $[6,7,10,17]$.

\section{Enhancing social medial and digital journalism risk community participation and resilience in frontline, recovery and rebuilding in public health emergencies processes}

Our findings showed that increasing digital, mobile and social media users dependence in enhancing social medial and risk community participation and resilience in frontline, recovery and rebuilding 
public health benefits, albeit challenges and issues. Increasing social media interaction between the patient and healthcare practitioner can be used to provide real time information during emerging epidemics and humanitarian crisis response. The widely use of social media in Africa is facing to some challenges and issues as the lack of policy and regulations as well as the lack of foundational infrastructures (i.e.: ICT and electricity), accessibility of social media is also limited by the low connectivity and the cost of the broadband internet in most the African countries. Furthermore, the social media is used for public health surveillance by collecting data on patient experiences and their opinions but also raised awareness for campaigns, preventive actions and positive behavior change programs. The main features that can be found in the majority of the social media platforms were interactive message content, digital voice and videos forms. However, social media and journalism backslashes such as fake news and misinformation can be used to promote cyber security, data privacy, cultural context and rights concerns require urgent attention both by stakeholders and the users/consumers (Table 2).

However, the proliferation of communication technologies miniature TVs, handheld radios, and personal computer companions such as Blackberry and Palm Pilot contribute to the omnipresence of the media in daily life and collaborative data-driven decisions policy and performance management based on strategic content and feedbacks. Moreover, a growing proportion of "life experience" is mediated through social media networks communication technologies instead of being directly experienced or witnessed [12,15]. Public health policymakers and community still undervalue the importance and power of social media uses in shaping public health actions, and emergency events mitigation and prevention. Community-based through a combination of radio, cell phones and computers via websites and social media behavioral and societal changes in public health emergencies and humanitarian crises response preparedness stakeholders roles and capacities in communication, their potential forms of organization and the use of media, channels and infrastructure [26-29]. Enhancing social communication services corporate responsibility roles, particularly in the field of disaster management. But, also transparent, accurate and proactive messaging need to be not only clear and concise. In today's business climate, it is even more important for practitioners to monitor and engage in newsgroups, forums, bulletin boards and other social media $[18,23]$. Whilst monitoring messages for abuse, businesses must be prepared equally to accept negative criticism, respond and rectify situations appropriately if genuine relationships of trust are to be established interest may violate other traditional scientific norms and untrained in risk communication.

Conventional and non-conventional social media, mobile and others internet communication platforms are largely used for sharing, networking, and connectedness, proactive, had to activate its plan to reassure the general public response and deployment emergency services could not be sufficient to embark on various communication strategies respond to community needs in the field of health, education and social justice [26]. It is thus essential to underscore the need for a stronger conceptual underpinning of social medial and e-Health communication interventions in relation to the pathway to social and behavior change for different demographics and audience segmentation of various ICT and telecommunications players. Moreover local government authorities could employ social media such as Facebook, Twitter, Mxit and other relevant sites to build relationships, to engage in conversations, to educate and prepare the community in advance and not only to respond in cases of emergency engagement without seeking to better understand what support local media needed to respond to the information needs $[5,8,11,13,26]$. While social media platforms are appropriate for message internationality in health education, they may not be particularly effective in addressing underlying structural issues and deep-seated cultural practices. All the same, strengthening social journalism in healthcare coverage and uptake adherence dwindling, enhanced communication through inexpensive methods is most needed in advancing universal health coverage and sustainable development goals impact in sub-Saharan

\begin{tabular}{|c|c|c|c|c|c|c|c|}
\hline & Social media & & Advantages/ Benefit & & Main Features & & Challenge and issues \\
\hline $\begin{array}{l}1 . \\
2 . \\
3 . \\
4 . \\
5 . \\
6 .\end{array}$ & $\begin{array}{l}\text { Facebook } \\
\text { Whatsapp } \\
\text { YouTube } \\
\text { Twitter } \\
\text { Instagram } \\
\text { Radio, TVs } \\
\text { and portable } \\
\text { computer/ } \\
\text { laptops }\end{array}$ & $\begin{array}{l}2 . \\
3 . \\
4 . \\
5 . \\
6 . \\
7 . \\
8 . \\
9 . \\
10 . \\
11 .\end{array}$ & $\begin{array}{l}\text { Increase interactions between } \\
\text { patients and public health } \\
\text { practitioner } \\
\text { Data and information social network } \\
\text { platforms } \\
\text { Communicate in terms of crisis } \\
\text { (provide minute by minute } \\
\text { information to public) } \\
\text { Empowerment and resiliency } \\
\text { building through information delivery } \\
\text { of real time updates on threats and } \\
\text { epidemics or disaster/ political/civil } \\
\text { unrest } \\
\text { Building awareness and } \\
\text { transmission of preventive } \\
\text { knowledge amongst frontline } \\
\text { healthcare practitioner } \\
\text { Raise awareness for campaigns } \\
\text { and programs } \\
\text { Provide answers to medical } \\
\text { questions } \\
\text { Collect data on patient experiences } \\
\text { and opinions } \\
\text { Health intervention, health } \\
\text { promotion or education } \\
\text { Sharing resources and public health } \\
\text { surveillance } \\
\text { Communicate with public in } \\
\text { surveillance and interventions }\end{array}$ & $\begin{array}{l}1 . \\
2 . \\
3 . \\
4 . \\
5 . \\
6 . \\
7 . \\
8 .\end{array}$ & $\begin{array}{l}\text { Generating awareness and } \\
\text { education through message } \\
\text { content and videos } \\
\text { Social network advertizing and } \\
\text { marketing } \\
\text { Social advocacy and political } \\
\text { campaigns by interactive voice } \\
\text { Auditing, monitoring and early } \\
\text { alert } \\
\text { Voice communication } \\
\text { Audio / Video clips } \\
\text { Digital forms } \\
\text { Detection, monitoring and } \\
\text { prevention of epidemics or } \\
\text { disaster }\end{array}$ & $\begin{array}{l}1 . \\
2 . \\
3 . \\
4 . \\
5 . \\
6 . \\
7 . \\
8 . \\
9 . \\
10 . \\
11 . \\
12 .\end{array}$ & $\begin{array}{l}\text { Lack of policy and regulations } \\
\text { Lack of foundational infrastructures } \\
\text { ( ICT infrastructures, electricity) } \\
\text { Lack of consistence and } \\
\text { confidence, and low subscription } \\
\text { Misinformation, low search visibility } \\
\text { and non-compliance } \\
\text { Cyber-attacks and ransome } \\
\text { Lack of freedom of expression and } \\
\text { maintenance of reputation } \\
\text { Inaccurate relevance and valuable } \\
\text { content } \\
\text { Low and costly broadband internet } \\
\text { connectivity } \\
\text { Illiteracy and abbreviations } \\
\text { Limited technical experiences } \\
\text { Fake news, Fake accounts and low } \\
\text { digital literacy } \\
\text { Oversaturation }\end{array}$ \\
\hline
\end{tabular}

Table 2: Potential use of social media and digital journalisms challenge and issues, and benefits in Africa. 
Africa. In such, to learn how to communicate risks in a responsible and transparent risk communities-based approaches that protects people's health, safety and rights, but also how to quickly share vital information on the current emergency event(s) and trend with partners to ensure an effective engagement and increase rapid response deployment for better health outcomes and wellbeing $[6,10,26,27,30]$. However, it would be necessary to consider their effectiveness and sustainability. Practical field experience seems to indicate that the deployment of social media for public health delivery is being viewed as another 'pet project syndrome' of development agencies for their branding and visibility approach of response to one of risk reduction prevention through the provision of adequate and timely information to the public and the risk of panic resulting from such information is always a deliberate act [17].

Improving social media and social journalism best practice through adherence to laws and regulations in communication interventions and more transparency is branded for specific agencies with coordination linkages and programs to enhance their effectiveness. Strategic alignment of social media and mobile health communication interventions can also play an important role in gaining the attention of specific opinion leaders, including politicians, governmental regulators, community leaders, and corporate executives, among others. This will be more impactful rather than the current fragmentary mass media efforts supported by different development local radio government and private agencies and subspecialty expertise on emerging threats infectious diseases epidemics available broadly via video, giving patients new access to information [12,21,28]; while also favorably positioning the experts and technical assistance in providing continuing social medial and digital education asynchronously and on a global scale of online corporate(public-private) social investment initiatives in boosting learning communities culture, roles and responsibilities in controlling hazardous materials and minimizing public health disaster crises emergencies impacts and losses $[29,30,31]$. Bolstering integrated social journalism approaches and strategies include greater health sector accountability and service delivery in upholding humanity core values, culture and best practice in conflict and disasters public health emergencies interventions can improve long-term health outcomes and economy prosperity worldwide [32-34].

\section{Conclusions}

Investing in social media and digital journalism approaches and strategies in public health emergencies risk communication preparedness and health preventive news is urgent to create innovative, better and healthier media opportunities and capabilities in providing better understanding of why, how and when to timely act and response to public emergencies needs and communities issues in Africa and elsewhere. This is crucial in building capacity and further reinforcing extremely valuable risk communication strategies for more productive and transformative community engagement and participatory empowerment. Effective and sustained production and advocacy for positive individual and citizenry added-value culture, behaviour and attitudes transformation based on quality health risk communication strategies that provide advertising entertainment, gamification and Internet-based solutions, while tackling operational local and global social journalism and social media backslashes and challenges. Those behavioral and societal changes is an essential part of an effective response is a key public health intervention during public health emergencies response and preparedness, risk communication and community engagement best practices as a key part of health operations in the WHO Emergency Response Framework. It is very important for African countries such as ours to take part in risk communication multi-disciplinary capacity building in upholding communities' confidence, trust and resiliency towards humanitarian emergencies crises free generations.

\section{Impact}

Social journalism and social media have been responsible for relevant behavioural and socio-economic changes during epidemics and disasters crises management.

Understanding community perceptions of risk and adapting communication messages, materials and strategies require meaningful engagement with those affected and involved.

There is an urgent need to improving digital journalism practice in communication safety, care delivery and rapid response effectiveness.

\section{References}

1. Khan S, Mishra JL, Elaine Lin KH, Doyle EH (2017) Rethinking communication in risk interpretation and action. Natural Hazards 88: 1709-1726.

2. Lent LG, Hande Sungur, Kunneman FA, Velde BV, Das E (2017) Too Far to Care? Measuring Public Attention and Fear for Ebola Using Twitter. Med Internet Res 19: e193.

3. Tambo E, Madjou G, Wandabwa CK, Tekwu EN, Olalubi OA, et al. (2016) Can free open access resources strengthen knowledge-based emerging public health priorities. Policies and programs in Africa? Version 1. F1000Res 5: 853

4. Tambo E (2014) Non-conventional humanitarian interventions on Ebola outbreak crisis in West Africa: health, ethics and legal implications. Infect Dis Poverty 3: 42.

5. WHO (2015) Ebola data and statistics: Ebola situation report

6. Tambo E, Chryseis F, Chengho, Ugwu CE, Wurie I, et al. (2017) Rebuilding transformation strategies in post-Ebola epidemics in Africa. Infect Dis Poverty 6: 71

7. Dahm MR, Georgiou A, Westbrook JI, Greenfield D, Horvath AR, et al. (2018) Delivering safe and effective test-result communication, management and follow-up: a mixed-methods study protocol. BMJ Open 8: e020235.

8. Guerrier G, Guerrier G, Sjögren L, Guerrier M, Bretonnière S, et al. (2015) Scientific journalism in Africa to help fight global health emergencies. The Lancet 386: 851

9. Kostkova P (2015) Grand Challenges in Digital Health. Front Public Health 3

10. Salmon CT, Arkins C (2003) Using Media Campaigns for Health Promotion. 449-472.

11. Gaby-Fleur Böl (2016) Risk communication in times of crisis; Pitfalls and challenges in ensuring preparedness instead of hysterics. EMBO Rep 17: 1-9.

12. Adebayo G, Neumark Y, Gesser-Edelsburg A, Ahmad WA, Levine H (2017) Zika pandemic online trends, incidence and health risk communication: a time trend study. BMJ Glob Health 2: e000296.

13. Liu JS, Ching Ho MH, Lu LY (2017) Recent Themes in SocialNetworking Service Research. PLoS One 12: e0170293.

14. Kummervold PE, Schulz WS, Smout E, Luque LF, Larson HJ (2017) Controversial Ebola vaccine trials in Ghana: a thematic analysis of critiques and rebuttals indigitalnews. BMC Public Health 17: 642

15. Hai Fung IC, Yi Hao, Jingxian Cai, Yuchen Ying, Schaible BJ, et al. (2015) Chinese Social MediaReaction to Information about 42 Notifiable Infectious Diseases. PLoS One 10: e0126092.

16. DiStaso MW, McCorkindale T, Wright DK (2011) How public relations executives perceive and measure the impact of social media in their organizations. Public Relations Review 37: 325-328.

17. Wilson AM, Henderson J, Coveney J, Meyer SB, Webb T, et al. (2014) Media actors' perceptions of their roles in reporting food incidents. BMC Public Health 14: 1305. 
Citation: Tambo E, Kazienga A, Fogang M (2018) Digital Journalism and Risk Communication Practice for Public Health Humanitarian Emergencies Response in Africa. J Mass Communicat Journalism 8: 383. doi: 10.4172/2165-7912.1000383

Page 9 of 9

18. Rosenbaum L (2015) Communicating uncertainty-Ebola, public health, and the scientific process. N Engl J Med 372: 7-9

19. Enia J (2013) The spotty record of Hyogo Framework for Action: Understanding the incentives of national disaster politics. The Social Science Journal 50: 213-224.

20. Gesser-Edelsburg A, Shir-Raz Y, Hayek S, Sassoni-Bar O (2015) What does the public know about Ebola? The public's risk perceptions regarding the current Ebola outbreak in an as-yet unaffected country. Am J Infect Control 43: $669-675$

21. Ratzan SC, Moritsugu KP (2014) Ebola crisis-communication chaos we can avoid. J Health Commun19: 1213-1215.

22. Massey E, Smith J, Roberts B (2017) Health needs of older populations affected by humanitarian crises in low- and middle-income countries: a systematic review. Confl Health 11: 29.

23. Kim SC, Shah DV, Namkoong K, McTavish FM, Gustafson DH (2013) Predictors of Online Health Information Seeking Among Women with Breast Cancer: The Role of Social Support Perception and Emotional Well-Being. J Comput Mediat Commun 18: 98-118.

24. Tennant JP, Waldner F, Jacques DC, Paola Masuzzo, Collister LB, Hartgerink $\mathrm{CH}$ (2016) The academic, economic and societal impacts of Open Access: an evidence-based review. Version 3. F1000Res 5: 632.

25. DeTolly K, Benjamin F (2011) Mobile Phones: Opening New Channels for Health Communication. 163-166.

26. Guerrier M, Sjögren L, Bretonniere S (2015) Reported incidents in the Ebola crisis in Guinea, Liberia and Sierra Leone: a systematic review of newspapers. 19-21.
27. Young S, Cumberland W, Lee SJ, Jaganath D, Szekeres G, et al. (2013) Social Networking Technologies as Emerging Tools for HIV Prevention: A Cluster Randomised Trial. Ann InternMed 159: 318-324

28. Okada N, Matsuda Y (2005) Risk communication strategy for disaster preparedness viewed as multilateral knowledge development. IEEE 640-647.

29. Kate Kahle, Sharon AJ, Tsabari AB (2016) Footprints of Fascination: Digita Traces of Public Engagement with Particle Physics on CERN's Social Media Platforms. PLoS One 11: e0156409.

30. Hai Fung IC, Fu KW, Chan CH, Bun Chan BS, Cheung CN, et al. (2016) Social Media's Initial Reaction to Information and Misinformation on Ebola, August 2014: Facts and Rumors. Public Health Rep 131: 461-473.

31. Natalie Henrich, Bev Holmes (2010) What the Public Was Saying about the H1N1 Vaccine: Perceptions and Issues Discussed in On-Line Comments during the 2009 H1N1 Pandemic. PLoS One 6: e18479.

32. Wright DK, Hinson MD (2010) An analysis of new communications media use in public relations: Results of a five-year trend study. Public Relations Journal 4: 1-27.

33. Ouedraogo DE (2015) Ebola virus disease: which lessons learnt and which riposte strategies for unreached countries near outbreak areas? Targeting Ebola world congress. Paris 28-29.

34. Fallah M, Skrip LA, d'Harcourt E, Galvani AP (2015) Strategies to prevent future Ebola epidemics. Lancet. 386: 131. 